\title{
Corrosion-induced cracking and bond behaviour of corroded reinforcement bars in SFRC
}

\author{
Carlos G. Berrocal ${ }^{* 1,2}$, Ignasi Fernandez ${ }^{1}$, Karin Lundgren ${ }^{1}$, Ingemar Löfgren ${ }^{1,2}$ \\ ${ }^{1}$ Division of Structural Engineering, Department of Civil and Environmental Engineering, Chalmers \\ University of Technology, SE-412 96, Göteborg, Sweden \\ 2 Thomas Concrete Group AB, \\ *Corresponding author. Telephone:+46 317722262, email: carlos.gil@chalmers.se
}

\begin{abstract}
This paper investigates, experimentally and numerically, the effect of fibre reinforcement on the initiation of corrosion-induced cracks in concrete and the bond behaviour of corroded reinforcement bars in fibre reinforced concrete. The fibres, due to their confining effect, contributed to delay crack initiation, improve the post-peak bond behaviour and retain the initial splitting strength for corrosion levels of up to $8 \%$. The mechanisms for delayed crack initiation were explained through 3D finite element analyses of the experiments whereas a 1D model, using experimental bond-slip curves as an input, was employed to quantify the beneficial effect of fibres on the reinforcement anchorage length.
\end{abstract}

Keywords:

A. Steel Fibres, B. Debonding, C. Finite Element Analysis (FEA), D. Mechanical testing, Corrosion-induced Cracking

\section{Introduction}

Corrosion of reinforcement remains the most common deterioration mechanism in reinforced concrete (RC) structures exposed to marine environments or de-icing salts. Corrosion does not merely affect the reinforcing steel by reducing its cross-sectional area and altering its mechanical properties [1], but it also affects the surrounding concrete. As corrosion proceeds, dissolved iron combines with oxygen and hydroxide ions to form corrosion products that accumulate at the steel-concrete interface. Owing to the greater volume of these products compared to the base steel, an internal pressure is generated which induces splitting stresses in the concrete surrounding the rebar. Upon prolonged corrosion, these splitting stresses can reach the tensile capacity of the concrete leading to cracking of the concrete cover. Eventually, additional cracks may develop leading to spalling of the cover, i.e. large fragments of concrete falling off, thus leaving the reinforcement bars exposed, which in turn accelerate the corrosion rate.

As splitting cracks develop, the confinement action of the concrete is rapidly decreased thereby reducing the bond capacity between steel and concrete and increasing the risk of anchorage failure [2]. Fibre reinforcement, which is widely known to effectively arrest tensile $[3,4]$ and bending $[5,6]$ cracks in concrete, may also be an effective way to control splitting cracks and preserve the bond capacity of corroded reinforcement bars. 
The beneficial effect of fibres on controlling splitting cracks stemming from rebar corrosion has been mentioned in the literature in several occasions. Available results showed that using fibre reinforced concrete (FRC) may significantly delay the appearance of corrosion-induced cracks [6-9]. However, the amount of fibres used in those studies was relatively high ( $>=1.5 \%$ vol.). For structural purposes, FRC is often likely to be combined with conventional reinforcing bars, using moderate fibre contents, as this is less expensive and easier to incorporate into the concrete mix. Furthermore, in the aforementioned studies, no relation between the degree of corrosion and crack initiation was specifically investigated and data regarding the role of fibre reinforcement at low fibre dosages on corrosion-induced cracking is lacking.

Regarding the bond behaviour of ribbed bars embedded in FRC, a significant amount of research has been carried out, including studies of different types of fibre, various fibre contents as well as monotonic and cyclic action, see e.g. [10-16]. Experimental results from different studies showed that, for low fibre contents, no significant influence of the fibres can be expected for well-confined concrete specimens exhibiting pull-out failure, see e.g. [11,17]. The effect of fibres becomes noteworthy when splitting failure occurs. In such cases, an increased bond strength and, particularly, a more ductile post-peak bond behaviour can be observed. However, experimental work addressing the influence of fibres on the bond behaviour of corroded reinforcement bars is very scarce in the literature. In fact, to the Authors' knowledge, only one relevant study [18] has been conducted, in which the role of polypropylene and nylon fibres at very low dosages on the bond between concrete and corroded rebars was investigated. Nevertheless, results from that study merely focused on the bond strength, disregarding the post-peak behaviour in which fibres have certainly a greater impact.

The present study aimed at investigating two distinct phenomena which have been seldom addressed in the past, namely: (a) the influence of steel fibres at low dosages on the onset of splitting cracks induced by corroding conventional reinforcement and (b) the bond behaviour of corroded reinforcement bars embedded in steel fibre reinforced concrete (SFRC). These aspects were addressed experimentally and the results include the degree of corrosion associated to crack initiation, crack width measurements of corrosion-induced cracks, the evolution of the bond strength with increasing corrosion and a comparison of the anchorage capacity based on the local bond-slip relationship obtained. Furthermore, 3D non-linear finite element (FE) analyses were carried out to simulate the pull-out tests and assess the applicability to FRC of a bond-corrosion model developed by Lundgren et al. [19], originally intended for plain concrete.

\section{Experimental programme}

In the present study, an experimental programme comprising 42 specimens was carried out. In order to assess the influence of fibres on the bond capacity of corroded reinforcement bars, pull-out tests were performed at three different corrosion stages. Accordingly, the specimens were divided into three groups: group I, uncorroded specimens used as reference samples; group II, specimens corroded up to the onset of corrosion-induced cracking; and group III, specimens corroded beyond the onset of splitting cracks. Furthermore, two different cover to bar diameter ratios were investigated for the bond-behaviour and a third one was included for the crack initiation stage. Table 1 summarizes the details of the experimental programme. The nomenclature of the specimens consists of three groups of characters indicating the type of concrete, either plain concrete (PC) or fibre reinforced concrete (FRC), the cover to bar diameter ratio and the corrosion stage. 
Table 1. Experimental programme

\begin{tabular}{|c|c|c|c|c|c|c|}
\hline \multirow[b]{3}{*}{$c / \varnothing$ ratio } & \multicolumn{6}{|c|}{ Corrosion stages and concrete type } \\
\hline & \multicolumn{2}{|c|}{$\begin{array}{c}\text { Group I } \\
\text { Uncorroded - Reference }\end{array}$} & \multicolumn{2}{|c|}{$\begin{array}{c}\text { Group II } \\
\text { Crack onset }\end{array}$} & \multicolumn{2}{|c|}{$\begin{array}{c}\text { Group III } \\
\text { High corrosion } \\
\end{array}$} \\
\hline & $\mathrm{PC}$ & FRC & $\mathrm{PC}$ & FRC & $\mathrm{PC}$ & FRC \\
\hline 2.5 & PC-2.5-Ref & FRC-2.5-Ref & $\mathrm{PC}-2.5-\mathrm{Cr}$ & FRC-2.5-Cr & PC-2.5-Cor & FRC-2.5-Cor \\
\hline 3.25 & - & - & $\mathrm{PC}-3.25-\mathrm{Cr}$ & FRC-3.25-Cr & - & - \\
\hline 4.0 & PC-4.0-Ref & FRC-4.0-Ref & $\mathrm{PC}-4.0-\mathrm{Cr}$ & FRC-4.0-Cr & PC-4.0-Cor & FRC-4.0-Cor \\
\hline
\end{tabular}

Note: Three specimens were cast for each combination of $c / \varnothing$ ratio and corrosion stage investigated.

\subsection{Specimen design and materials}

The specimens used were concrete cylinders reinforced with a single reinforcement bar placed along the cylinder axis and sticking out at one of the sides to enable electrical connections. The cylindrical shape of the specimens and the position of the rebar in the centre were chosen to obtain uniformly distributed corrosion around the rebar and minimize preferential cracking directions. The cylinders had a total height of $100 \mathrm{~mm}$ while the rebar was partially encased into a PVC tube, thus providing an effective bonded length of $70 \mathrm{~mm}$. Three different concrete cover to bar diameter ratios $(c / \varnothing)$ were investigated, namely $2.5,3.25$ and 4.0 , corresponding to cover depths of 40,52 and $64 \mathrm{~mm}$, respectively. As for reinforcement, $\varnothing 16 \mathrm{~mm}$ ribbed bars of steel class B500B were used. The geometry of the specimens is shown in Fig. 1 whereas geometrical information about the rib pattern, rib height and rib spacing of the rebars is presented in Fig.2 and Table 2.

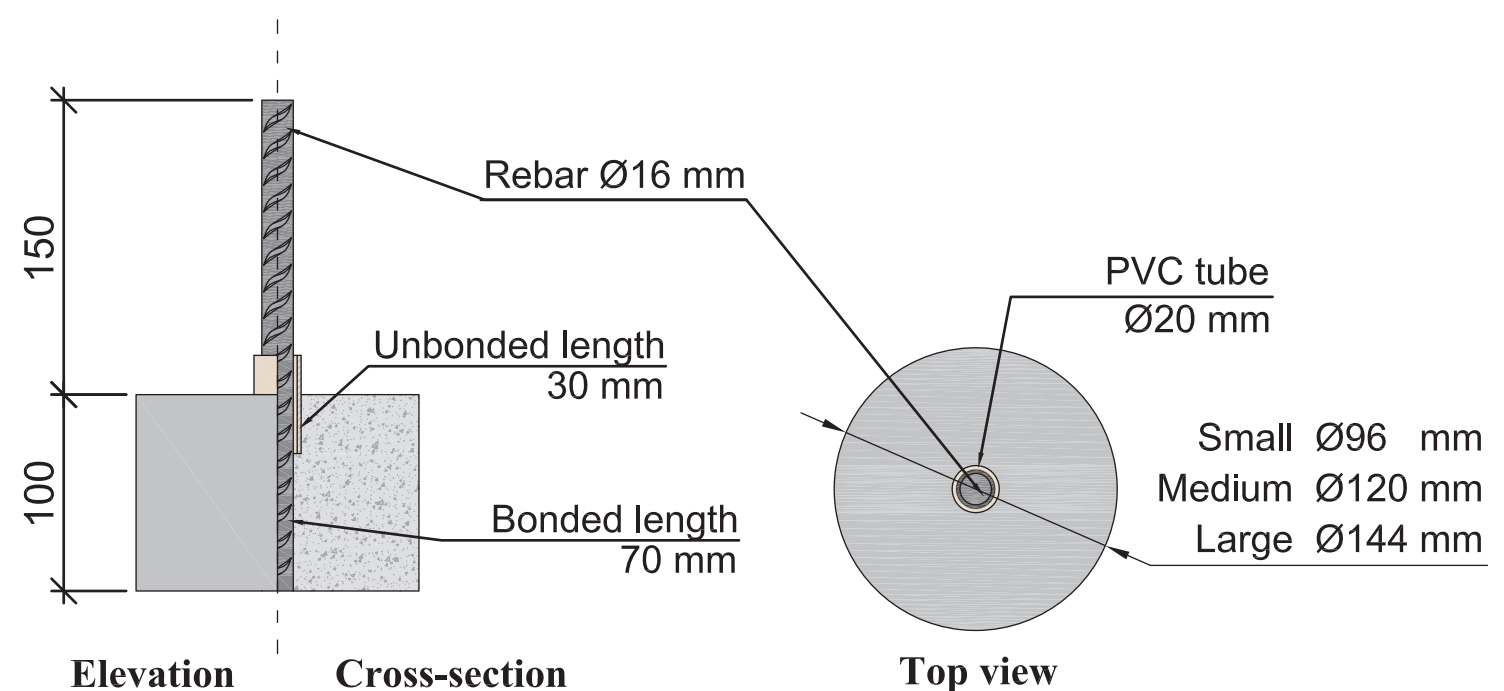

Figure 1. Specimen geometry. All measurements are in $\mathbf{~ m m}$. 

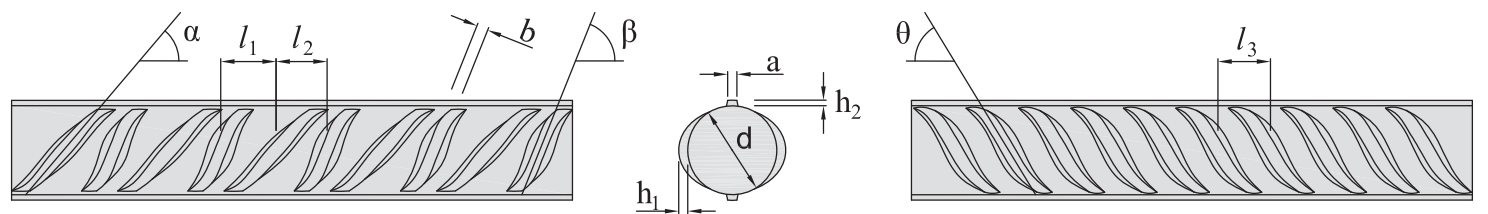

Figure 2. Geometry of ribbed reinforcement bars.

Table 2. Measured parameters describing the geometry of the ribbed reinforcement bars, in $\mathbf{m m}$.

\begin{tabular}{|c|c|c|c|c|c|c|c|c|c|c|c|}
\hline & $d$ & $a$ & $h_{1}$ & $h_{2}$ & $b$ & $l_{1}$ & $l_{2}$ & $l_{3}$ & $\alpha\left({ }^{\circ}\right)$ & $\beta\left(^{\circ}\right)$ & $\theta\left({ }^{\circ}\right)$ \\
\hline$\varnothing 16$ & 15.3 & 2.1 & 1.1 & 0.6 & 3.0 & 10.1 & 9.2 & 9.5 & 50 & 68 & 59 \\
\hline
\end{tabular}

A self-compacting concrete mix with a water to cement ratio $(w / c)$ of 0.47 was prepared to cast all the specimens using individual molds. The same mix composition was used to prepare both the plain and the steel fibre reinforced concrete, except for minor variations in the aggregate content to incorporate the fibres. Sodium chloride was incorporated into the mix at $4 \%$ by weight of cement with the intention of preventing the formation of the passive layer on the steel bar. End-hooked 35 $\mathrm{mm}$ long steel fibres were used as fibre reinforcement. Table 3 shows the detailed concrete composition.

Table 3. Concrete composition, in $\mathrm{kg} / \mathrm{m}^{3}$

\begin{tabular}{lcc}
\hline & \multicolumn{2}{c}{ Concrete mix designation } \\
\hline Component & PC & SFRC \\
\hline Cement (CEM I 42.5N SR 3 MH/LA) & 360 & 360 \\
Limestone filler (Limus 40) & 150 & 150 \\
Fine aggregate (sand 0/4) & 718 & 711 \\
Coarse aggregate (crushed 5/16) & 987 & 977 \\
Effective water & 169 & 169 \\
Superplasticizer - Glenium 51/18 & 5.4 & 6.48 \\
Air entrainer - MicroAir 105 & 0.36 & 0.36 \\
Sodium Chloride (NaCl) & 14.4 & 14.4 \\
Steel fibres - Dramix 65/35-BN & - & 40 \\
\hline
\end{tabular}

Material tests were carried out to assess the compressive strength, $f_{c m}$, and the splitting tensile strength, $f_{c t m, s p l}$, of both mixes. The tests were performed on three different specimens after a 28 days period of water curing. The compressive strength was tested on $100 \mathrm{~mm}$ cubes according to [20] while the splitting tensile strength was tested in accordance to [21] on $150 \mathrm{~mm}$ cubes. A summary of the material properties is presented in Table 4 . The residual tensile strength values of the fibre reinforced concrete mix, assessed in a previous study [22], for a mix with the same composition, according to EN-14651 [23] are presented in Table 5. 
Table 4. Material properties, in MPa

\begin{tabular}{ccccc}
\hline & \multicolumn{2}{c}{$f_{\text {cm (cube) }}$} & \multicolumn{2}{c}{$f_{\text {ctm,spl. }}$} \\
\hline & Avg. & Std. Dev & Avg. & Std. Dev \\
\hline PC & 56.0 & 1.3 & 4.2 & 0.2 \\
FRC & 52.5 & 0.3 & 4.6 & 0.2 \\
\hline
\end{tabular}

Table 5. Average residual flexural tensile strength of FRC according to [23].

\begin{tabular}{ccc}
\hline $\begin{array}{c}\text { CMOD } \\
{[\mathrm{mm}]}\end{array}$ & $\begin{array}{c}\mathbf{f}_{\mathrm{R}} \\
{[\mathrm{MPa}]}\end{array}$ & $\begin{array}{c}\boldsymbol{C O V} \\
{[\%]}\end{array}$ \\
\hline 0.5 & 4.99 & 7.9 \\
1.0 & 4.69 & 6.7 \\
1.5 & 4.44 & 8.2 \\
2.0 & 4.14 & 13.5 \\
2.5 & 3.79 & 16.4 \\
\hline
\end{tabular}

\subsection{Casting and curing}

All the specimens of the same concrete mix were cast in a single batch and were demoulded $24 \mathrm{~h}$ after casting. Subsequently, the specimens in Group I were stored in potable water and cured for a period of 85 days until they were subjected to the pull-out tests. Specimens in Group II and Group III were cured in $3.5 \% \mathrm{NaCl}(35 \mathrm{~g}$ of $\mathrm{NaCl} / 1)$ solution until the initiation of the accelerated corrosion procedure for 58 and 35 days, respectively. The pull-out tests for the specimen in Group II and Group III, were carried out at the age of 85 and 132 days, respectively. During the curing period as well as during the accelerated corrosion procedure, all of the specimens were kept in a room at a constant temperature of $22^{\circ} \mathrm{C}$.

\subsection{Experimental setup}

The experiments carried out in the present investigation were divided into two phases involving different test procedures. First, the specimens were subjected to accelerated corrosion by impressing a DC current for a period of time during which crack initiation was monitored through electrical resistance measurements as well as visual inspection. The second part of the experiments involved the determination of the bond-slip relationship of corroded and reference specimens by means of pullout tests. After the pull-out tests, the corroded reinforcement bars were chemically cleaned and their corrosion level was assessed by gravimetric methods. All the procedures are described in the following.

\subsubsection{Accelerated corrosion tests}

As the time needed to observe corrosion-induced splitting cracks on naturally corroded structures could be excessively long, accelerated corrosion tests were carried out in order to hasten the rate of 
steel dissolution. A novel setup was conceived in order to reach a compromise between the geometrical requirements imposed on the specimens by the pull-out tests and the need of determining the onset of splitting cracks during the accelerated corrosion phase while ensuring uniform distribution of corrosion along the rebar.

A $1 \mathrm{~mm}$ thick copper wire mesh, spanning the entire height of the cylinders, was fastened around the specimens using rubber bands. The specimens were introduced into plastic buckets with the reinforcement bar passing through a hole previously bored at the centre of the bucket. Silicone was applied at the cylinder-bucket interface in order to create a watertight seal. After a $24 \mathrm{~h}$ period during which the silicone was left to harden, the buckets were filled with $3.5 \% \mathrm{NaCl}$ solution, setting the water level about $2 \mathrm{~cm}$ below the top of the cylinders to prevent the formation of a continuous conductive path between the mesh and the rebar. Fig. 3 illustrates the setup of the accelerated corrosion tests.

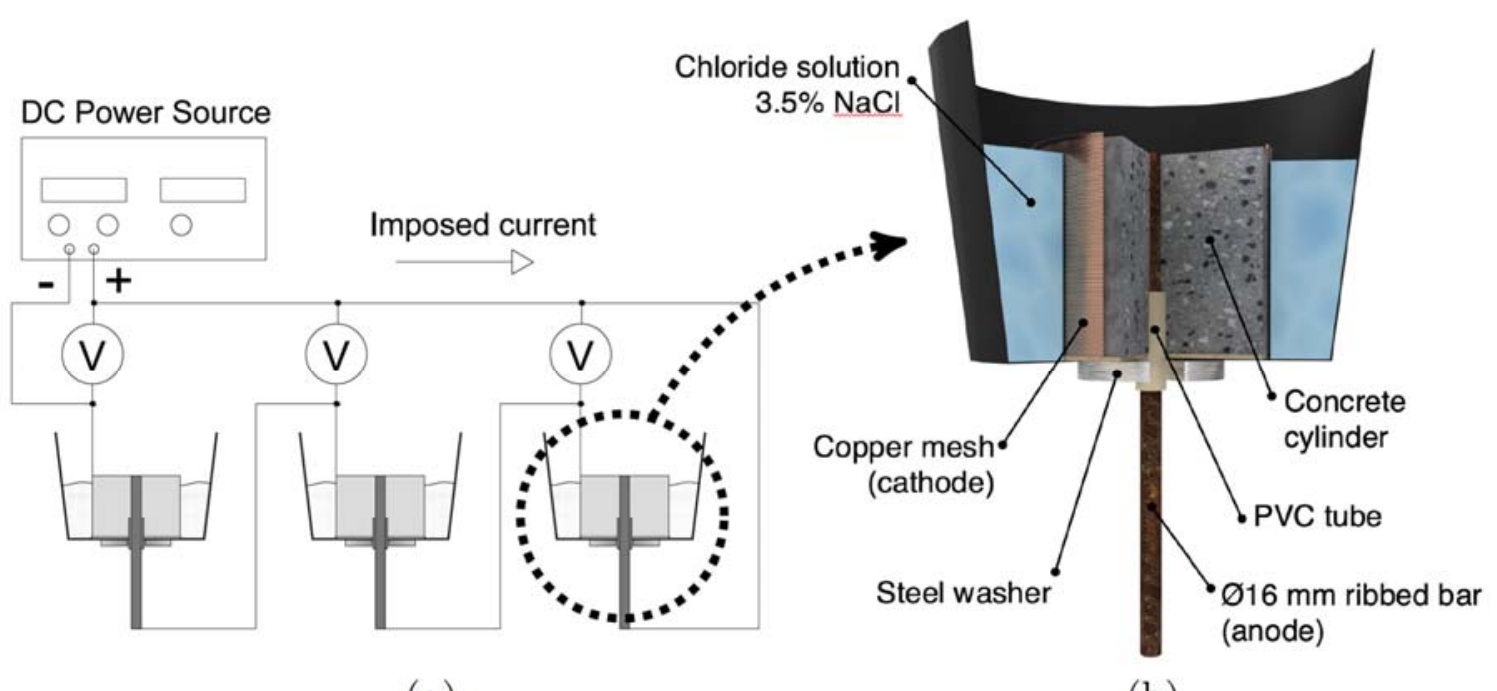

(a)

(b)

Figure 3. Accelerated corrosion setup

Leads were attached to the reinforcement bar, acting as anode, and to the copper mesh, acting as cathode, to connect the specimens in series as schematically depicted in Fig. 3. Previous investigations using impressed current to accelerate the corrosion process have reported that current densities above a certain threshold $\left(350 \mu \mathrm{A} / \mathrm{cm}^{2}\right.$ according to [24]) may result in deviation of the test conditions from the natural corrosion process. Consequently, a current density of $100 \mu \mathrm{A} / \mathrm{cm}^{2}$ was applied through the circuit using a DC power source and a current regulator.

The electrical resistance of each specimen was monitored during the entire duration of the accelerated corrosion tests to determine the point in time when corrosion-induced cracking initiated. The voltage across the cathode and anode of each specimen was measured and recorded hourly using a data logger. Subsequently, the electrical resistance was calculated, according to Ohm's law, as the quotient between the measured voltage and the applied current. In addition to electrical resistance measurements, a crack microscope with $20 \mathrm{x}$ magnification and a $0.02 \mathrm{~mm}$ resolution scale was employed to visually confirm the first crack appearance in the specimens belonging to Group II.

Specimens in Group II were subjected to accelerated corrosion until cracking was visually confirmed. Thereafter, the specimens were removed from the circuit and remained stored in potable water until 
they were subjected to the pull-out tests. Specimens in Group III, on the other hand, were subjected to accelerated corrosion beyond the cracking point, for a period approximately four times longer than the time of the latest specimen in Group II to crack. Thus, while all the specimens in Group II were corroded for 4 weeks or less, corrosion was enforced to specimens in Group III for a period of 14 weeks.

\subsubsection{Pull-out tests}

The setup for the pull-out tests is schematically presented in Fig. 4. The specimens were supported on a steel plate mounted on the top of the loading rig, using a sheet of Teflon between the plate and the specimen to reduce friction. The reinforcement bar, passing through the steel plate, was attached to a longer steel rod using a wedge lock. The rod, outfitted with a bolt head at the opposite end, was anchored at a load cell fastened to the movable frame of the load rig. The maximum load of the load cell was $100 \mathrm{kN}$ with an accuracy of $0.1 \mathrm{kN}$. The free-end slip of the embedded reinforcement was measured with a linear variable displacement transducer (LVDT) supported with a tripod on the top surface of the concrete cylinder. The measuring range of the LVDT was $\pm 5.000 \mathrm{~mm}$ with an accuracy of $0.001 \mathrm{~mm}$. The pull-out tests were performed with a constant displacement rate of $0.2 \mathrm{~mm} / \mathrm{s}$. Both the load and displacement data were recorded using a data logger at a frequency of 10 samples per second.

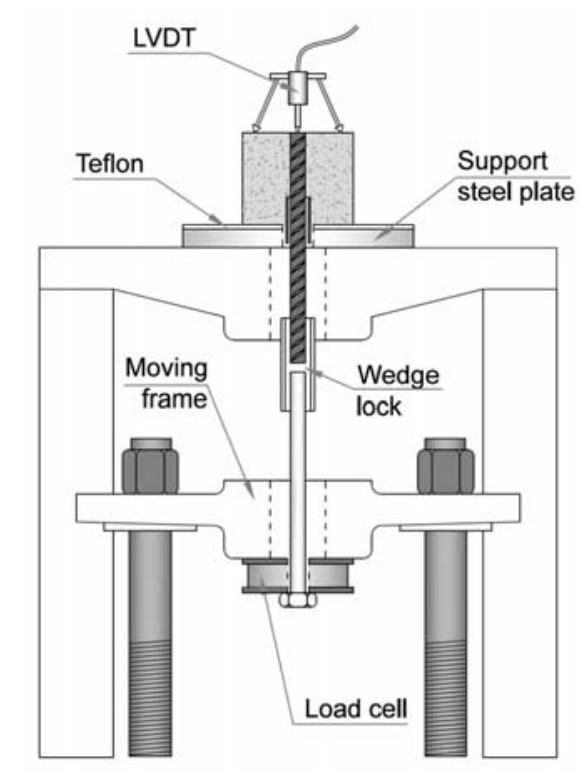

Figure 4. Pull-out test setup

\subsubsection{Removal of corrosion products and assessment of the corrosion level}

After having carried out the pull-out tests, the reinforcement bars were extracted from the concrete cylinders and cleaned for gravimetric steel loss measurements. Corrosion products and small pieces of concrete adhering to the rebar were chemically removed according to ASTM recommendations [25] by reiterated immersion of the bars in a solution of hydrochloric acid and urotropine. In this study, the corrosion level was defined as the steel loss, assumed to be concentrated and uniformly distributed along the $70 \mathrm{~mm}$ of bar embedded in the concrete and calculated according to Eq. 1:

$v=\frac{k \cdot M_{0}-M_{f}}{k \cdot M_{0}} \cdot \frac{L_{t o t}}{L_{b}} \cdot 100$ 
where $v$ is the corrosion level in $\%, M_{0}$ is the initial steel weight of the bar before casting, $M_{f}$ is the final weight of the corroded steel bar after acid cleaning, $L_{t o t}$ and $L_{b}$ are the total length and the bonded length of the rebar equal to $250 \mathrm{~mm}$ and $70 \mathrm{~mm}$, respectively, and $k$ is a parameter accounting for the loss of mill-scale of the bar due to acid cleaning. In this study, $k$, was experimentally determined to be 0.998 by subjecting non-corroded reinforcement bars, as received, to the same cleaning procedure used for the corroded rebar and measuring the loss of weight attributable to the removal of the millscale.

\section{Experimental results}

\subsection{Corrosion induced cracking}

In Fig. 5, an example of the electrical resistance results monitored during the tests is shown for selected specimens from Group II and III. The results are presented as a function of the corrosion level, which was obtained by assuming a constant corrosion rate and consequently a linear relationship between time and steel loss. Since corrosion was induced by impressing a constant current throughout the entire duration of the tests, the assumption was considered reasonable.
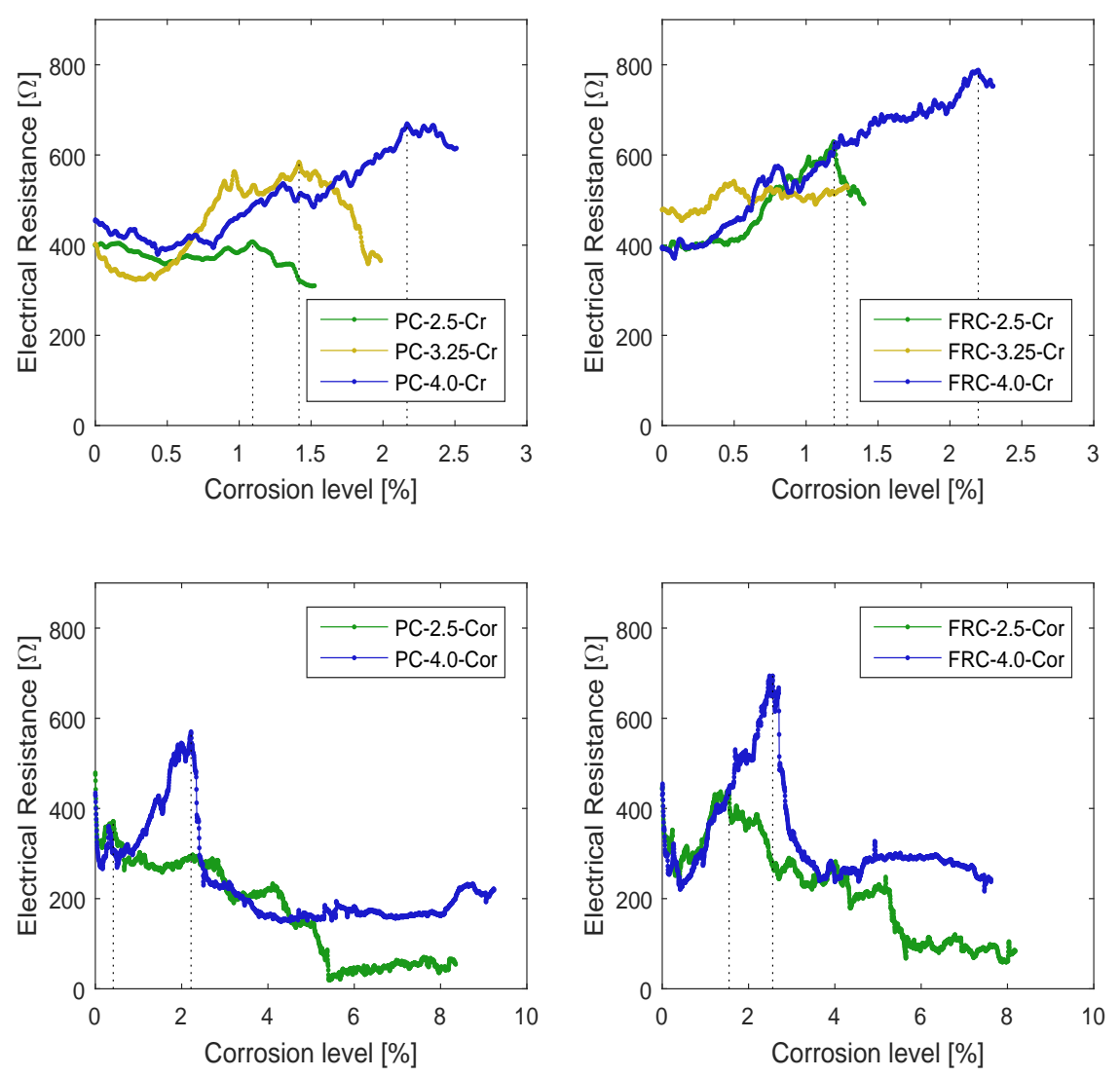

Figure 5. A sample of the evolution of electrical resistance throughout the accelerated corrosion procedure for selected specimens of Group II and Group III. Dotted vertical lines indicate the corrosion level at crack initiation. Note the different scale of the $x$-axis. 
Generally, the electrical resistance progressed in a similar manner in all cases: a slight decrease in the beginning, followed by a gradual increase until it finally dropped again. In specimens from Group II, crack initiation was determined as the moment when maximum electrical resistance was achieved immediately prior to visually detecting a crack. For specimens in Group III, crack initiation was assumed to happen at the moment when electrical resistance started decreasing with no subsequent significant increase. It should be noted that since crack onset was not visually confirmed for specimens in Group III, the results may be only considered as indicative. In Fig.5 crack initiation is indicated by dotted lines whereas Fig.6 presents a summary of the average corrosion level leading to crack initiation for each group, concrete mix and $c / \varnothing$ investigated. Note that in the present study, the term crack initiation is specifically used to refer to the moment when the first splitting crack propagated through the entire cover and reached the perimeter of the concrete cylinder, forming an electrolytic path between the embedded rebar and the external mesh which can be associated with the drop in electrical resistance shown in Fig.5. On the other hand, crack onset is used in a more general sense to refer to the period of time during which splitting cracks formed and propagated.

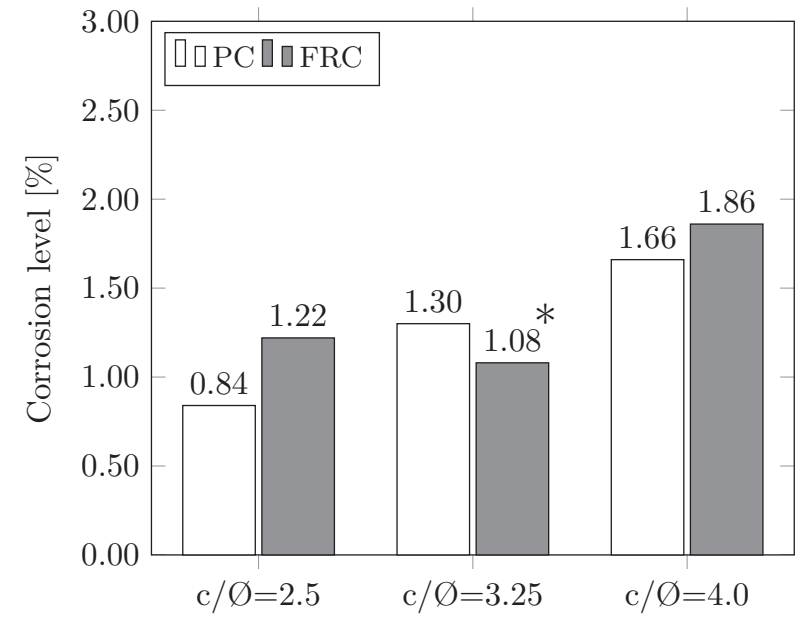

(a) Group II - Crack onset

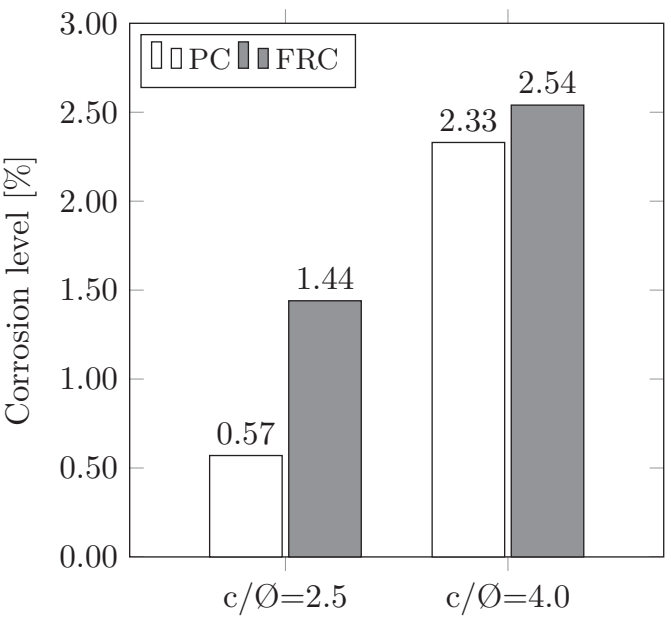

(b) Group III - High corrosion

Figure 6. Average corrosion levels at crack initiation. ${ }^{*}$ FRC-3.25-Cr specimens deviated from the general trend followed by the rest of specimens and were considered outliers.

Regarding the relation between corrosion level and crack initiation, the results presented in Fig.6 clearly show that, from the parameters investigated in this study, the $c / \varnothing$ played the most important role in delaying the initiation of corrosion-induced cracks, although its effect was more pronounced in PC specimens. Increasing the $c / \varnothing$ from 2.5 to 4.0, delayed crack initiation by a factor of 2 and 1.5 for PC and FRC specimens in Group II, respectively, whereas it delayed crack initiation by a factor of 4 and 1.75 for PC and FRC specimens in Group III, respectively.

Adding fibre reinforcement, had likewise a positive effect, although to a lesser degree compared to the $c / \varnothing$, in delaying crack initiation, which was particularly noticeable in specimens with a smaller $c / \varnothing$. Initially, it was believed that the explanation for that behaviour could be attributed to how the first corrosion-induced crack propagated through the specimens with a different cover depth; i.e. more gradually in small specimens allowing a greater contribution of the fibres and more suddenly in large 
specimens due to a higher built-up internal pressure. This hypothesis was in fact supported by electrical resistance measurements, which exhibited a sudden drop for large specimens and a more gradual decrease for small specimens, see Fig. 7. However, numerical results from the 3D FE analyses, showed an opposite trend, i.e. cracks propagating more gradually in large specimens compared to smaller ones. This is further discussed in Section 5.1.2.

For specimens in Group III, the crack pattern observed on the top surface of the specimens at the end of the accelerated corrosion procedure was documented and is presented in Fig.7. In all cases, multiple cracks developed, with one noticeably wider than the rest. The dominant crack is highlighted in Fig.7 by a thicker line width whereas the crack width of individual specimens, measured at the perimeter of the top surface, are listed in Table 6.

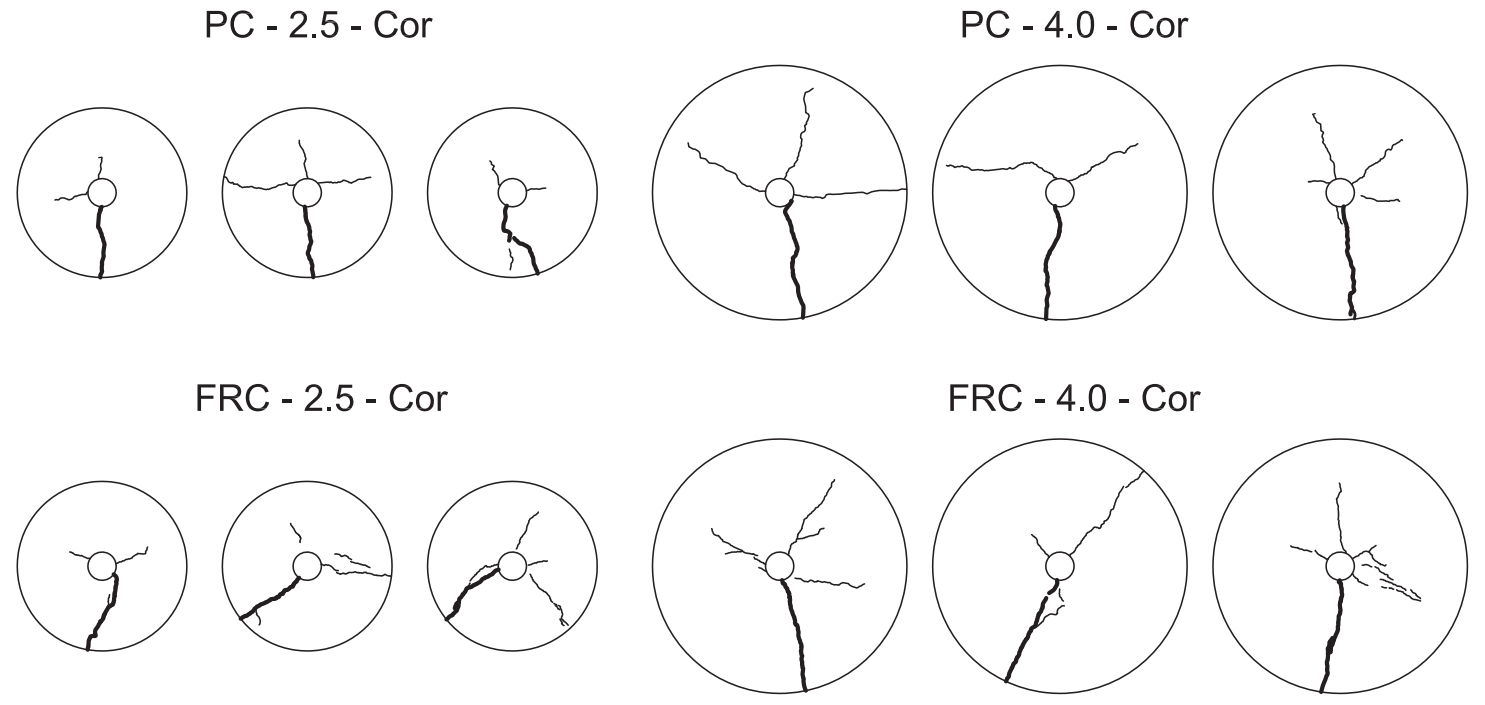

Figure 7. Crack pattern at the top surface of specimens in Group III. Main crack is represented with a thicker line width.

Table 6. Crack width of the widest crack measured at the perimeter of specimens in Group III, in $\mathbf{m m}$. The corrosion level determined at the end of the accelerated corrosion procedure, in $\%$, is given in brackets.

\begin{tabular}{ccc}
\hline $\mathrm{c} / \varnothing$ & 2.5 & 4.0 \\
\hline & $0.54(8.58)$ & $1.06(9.24)$ \\
PC & $0.82(8.48)$ & $0.98(8.43)$ \\
& $0.48(8.35)$ & $0.78(8.62)$ \\
& $0.26(8.57)$ & $0.54(7.62)$ \\
FRC & $0.46(8.18)$ & $0.52(7.72)$ \\
& $0.14(7.98)$ & $0.68(7.33)$ \\
\hline
\end{tabular}

It is worth noting that unlike previous investigations in which the use of higher fibre contents prevented the formation of corrosion-induced cracks for corrosion levels up to $10 \%$ (expressed as steel loss) [6,7], in the present study, with the cover depths investigated, using $0.5 \%$ vol. of steel 
fibres did not supress crack initiation beyond corrosion levels of about 1-2\%. However, an excessive delay of corrosion-induced cracks has raised concerns among some researchers who highlighted that the absence of such cracks and subsequent rust stains, which are unequivocal signs of ongoing corrosion, may mask the actual underlying problem and result in unexpected failure of the structure [26]. Nevertheless, a comparison of the widest measured crack revealed that cracks were roughly $50 \%$ wider for PC specimens compared to FRC specimens, at similar corrosion levels.

\subsection{Pull-out behaviour}

In Fig 8. the experimental bond-stress vs free-end slip curves obtained from the pull-out tests are presented. The bond stresses displayed in Fig. 8 represent an average stress value calculated as the ratio between the tensile load and the total surface of embedded reinforcement according to:

$\tau_{b}=\frac{F}{\pi \emptyset\left(L_{b}-s\right)}$

where $\tau_{\mathrm{b}}$ is the average bond stress, $F$ is the applied tensile load, $\varnothing$ is the nominal diameter of the rebar, $L_{\mathrm{b}}$ is the initial bonded length, equal to $70 \mathrm{~mm}$, and $s$ represents the free-end slip.
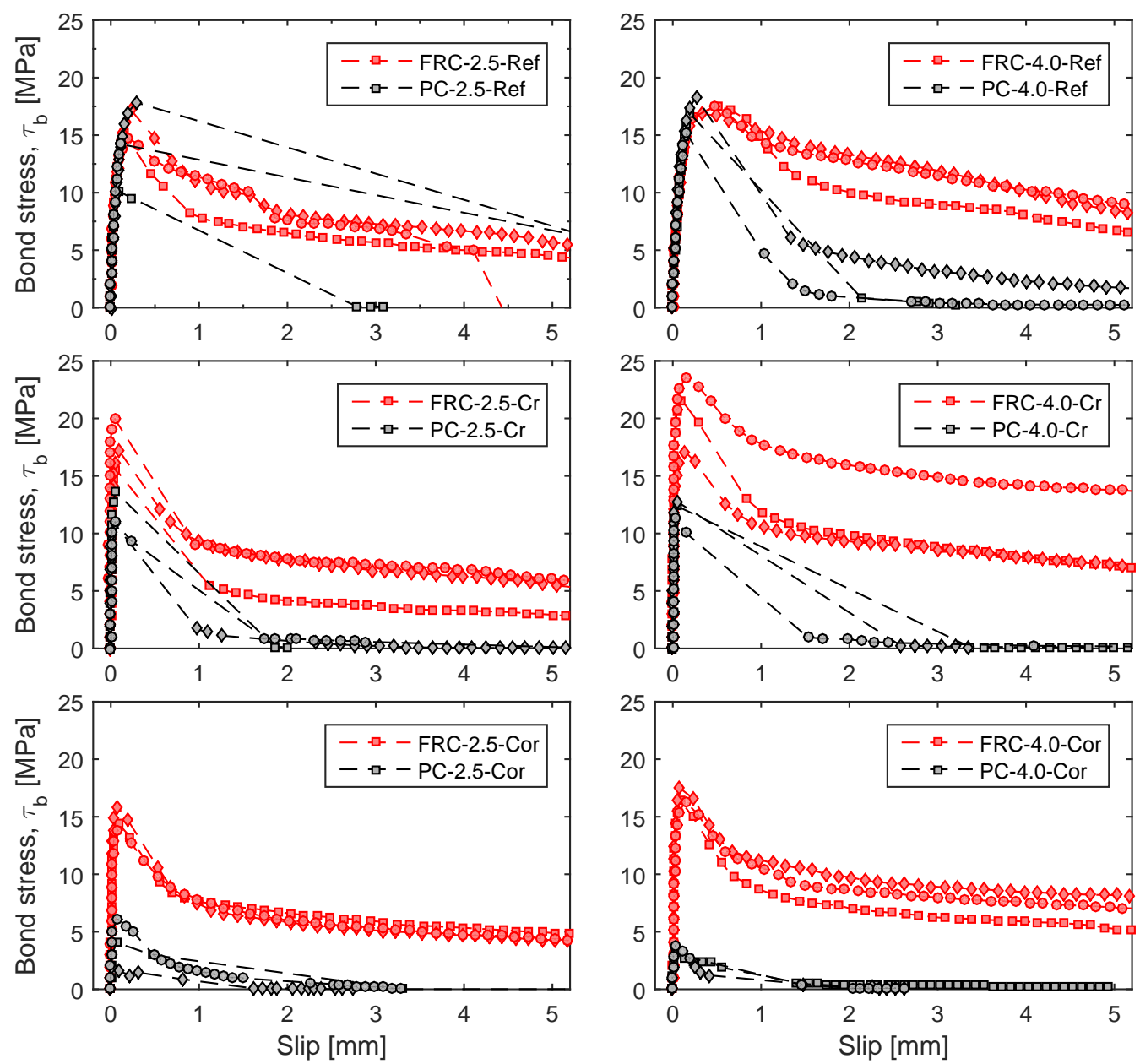

Figure 8. Bond stress versus free-end slip curves obtained from pull-out tests. 
Despite all the specimens tested in the present investigation exhibited splitting failure, a major difference between PC and FRC was observed during the pull-out tests. After reaching the peak strength, here referred to as splitting strength, $\tau_{\mathrm{sp}}$, PC specimens generally split into two or more pieces, thereby losing all the confinement provided by the cover. FRC specimens, on the other hand, were able to arrest splitting cracks and remain together in one piece, thus providing a significant amount of confinement even in the post-peak stage. An example of this observation is presented in Fig. 9, where the condition of the specimens in Group III after the pull-out tests is shown.

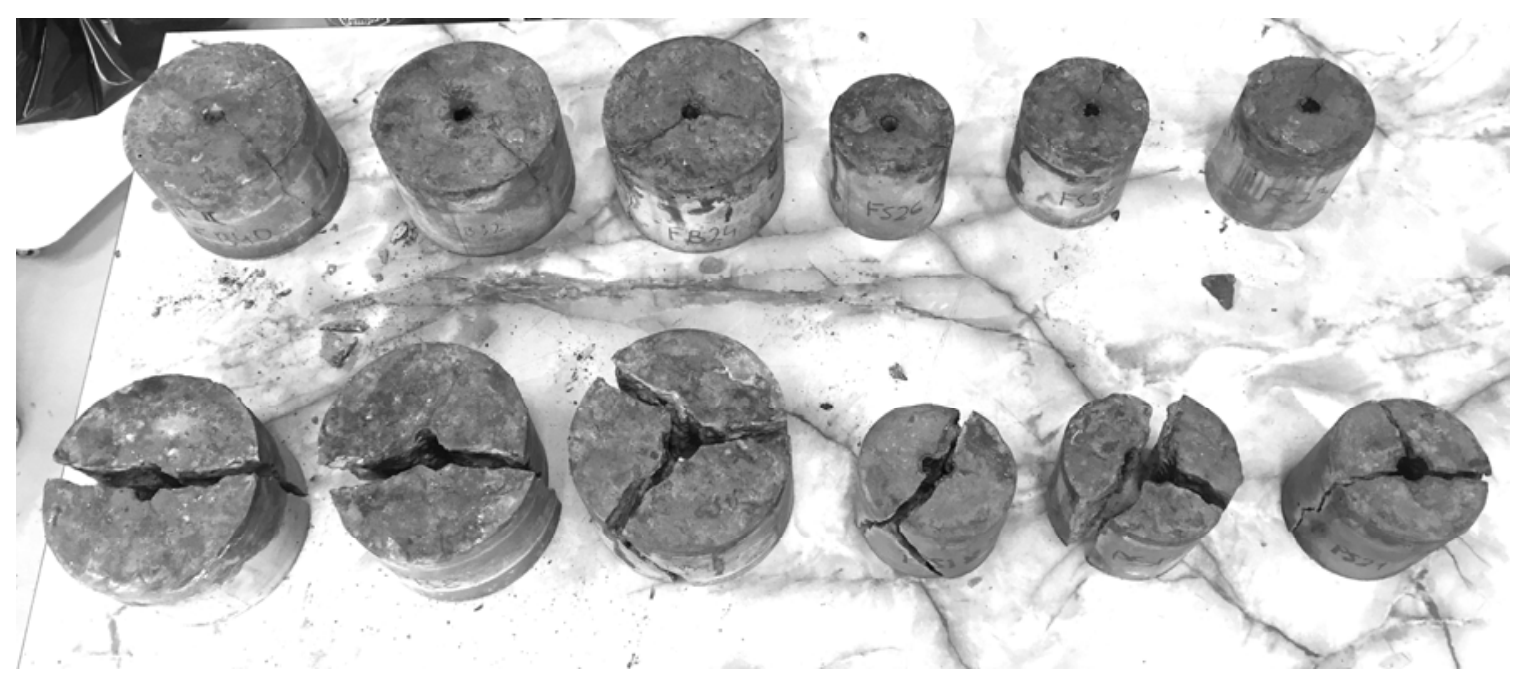

Figure 9. Specimens of Group III after the pull-out tests. PC specimens, split into various pieces, are lined at the front whereas FRC, still intact, are line at the rear.

Based on the capacity of the fibres to maintain the integrity of the concrete specimens even after the complete pull-out of the reinforcement bar, it can be argued that adding $0.5 \%$ of steel fibres may significantly contribute to prevent spalling of the cover, provided the performance of the crack bridging fibres is not compromised by corrosion.

As a direct consequence of the differences observed in the splitting failure of PC and FRC specimens, the results presented in Fig. 8 show an obvious distinction in their pull-out behaviour, regardless of the corrosion stage. The former suffered an abrupt loss of bond stress after reaching the splitting strength due to the sudden loss of confinement associated with the formation of splitting cracks, whereas the latter exhibited a smoother stress decay in the post-peak branch thanks to the crack control mechanism provided by the fibres. Moreover, after the splitting strength, the bond stress in PC specimens decreased rapidly and, in most cases, it was reduced to virtually zero at a slip of $2 \mathrm{~mm}$. On the other hand, FRC specimens were able to keep a residual bond stress of approximately $30 \%$ of the splitting strength at $5 \mathrm{~mm}$ slip throughout the various corrosion stages.

In order to compare the results of the PC and FRC specimens for the different covers and corrosion stages in detail, the splitting strength from each experimental curve is presented in Fig. 10 as a function of the corrosion level. As expected, for the reference group, there was not a significant difference between PC and FRC in terms of splitting strength since the fibres did not prevent cracking, whereas a small increase, attributable to the cover size, was apparent. Upon corrosion-induced cracking, PC specimens suffered a moderate reduction of the splitting strength whereas it slightly 
increased for FRC, an effect that may be attributed to a higher normal stress at the interface due to corrosion. Finally, at higher corrosion levels the remaining splitting strength of PC specimens was only a small fraction of the initial, with no apparent influence of the cover depth. Highly corroded FRC specimens, on the other hand, exhibited a nearly identical splitting strength as uncorroded one

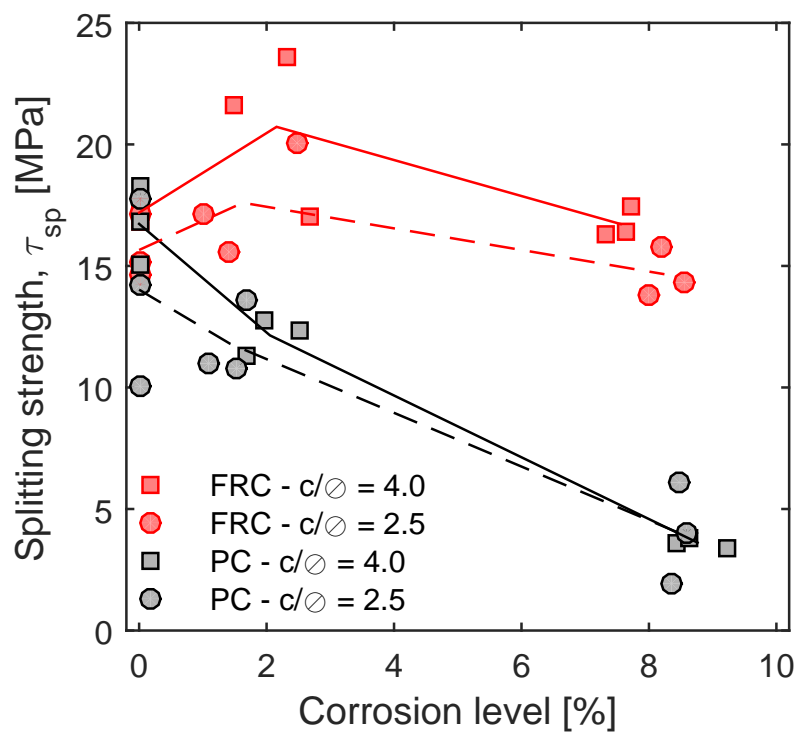

Figure 10. Splitting strength determined experimentally as a function of the corrosion level for PC and FRC (lines show the average behaviour).

\section{Modelling of reinforcement bond in concrete}

This section introduces two different approaches to model the bond behaviour of reinforcement in concrete, which have been used in the present work. The first approach consists in a 1D model used to evaluate and compare the experimental results from the pull-out tests by computing the required anchorage length needed to anchor the yield force from the measured local bond-slip. The second approach entails the use of non-linear finite element analyses of a 3D model carried out with the commercial software DIANA [27] in order to determine how accurately an existing bond-corrosion model developed for plain concrete, described in section 4.2.1, can reproduce the experimental bondslip behaviour observed in the present work.

\subsection{One dimensional model}

Lundgren et al. [28] presented and validated a 1D bond-slip model capable of analysing the bond stress-slip behaviour of corroded and uncorroded ribbed steel reinforcement. The model computes the anchorage capacity of the rebar by solving the differential equation describing the equilibrium between cross-sectional and bond stresses along the reinforcement as expressed by Eq. (3):

$$
\frac{\pi \emptyset^{2}}{4} \frac{d \sigma}{d x}-\pi \emptyset \tau_{b}=0
$$

where $\varnothing$ is the reinforcement diameter, $\sigma$ is the stress in the reinforcement and $\tau_{\mathrm{b}}$ is the bond stress. The model assumes infinitesimal strain theory, that the steel is in the elastic range and that the deformation of the surrounding concrete is negligible so that the slip can be considered equal to the 
steel displacement. Introducing these assumptions into Eq. (3) and including the appropriate boundary conditions for a bar of length $L$, the boundary value problem expressed by Eq. (4) can be formulated:

$$
\frac{\pi \emptyset^{2}}{4} E_{s} \frac{d^{2} s}{d x^{2}}-\pi \emptyset \tau_{b}(s)=0 ;\left.\quad \frac{d s}{d x}\right|_{(x=0)}=0 ; \quad s(x=L)=u_{L}
$$

where $E_{s}$ is the Young's modulus of steel, $s$ is the slip and $u_{L}$ is the prescribed displacement at one of the ends of the reinforcement bar. In the original model, the bond stress-slip relation, $\tau_{\mathrm{b}}(s)$ in Eq. (3), is assumed to follow an elasto-plastic law, whereas in the present study the bond stress-slip relations determined experimentally were used instead. Subsequently, the minimum length needed to fully anchor the yield force of a Ø16 reinforcement bar was calculated by numerically solving Eq. (4) with MATLAB $^{\circledR}$ [29] for each experimental bond-slip relation. Further information regarding the description and implementation of the model can be found in [28].

\subsection{Three-dimensional non-linear finite element analyses}

\subsubsection{Finite Element Model}

A 3D model of the specimens was created using solid mesh elements for both the concrete and the steel bar as illustrated in Fig 11. The element type used were triangular prisms with $\sim 6 \mathrm{~mm}$ base and $10 \mathrm{~mm}$ height. The unbonded length of the bar was modelled as a $3 \mathrm{~mm}$ gap corresponding to the difference between the external radii of the bar and the PVC tube. Boundary conditions were applied at the bottom surface of the concrete to restrain the vertical displacement (z-axis direction) as well as in the free end of the steel bar to prevent displacement and rotation in any direction, see Fig. 11. The reason to create supports at the end of the steel bar in the $z$-axis direction was to later assign a prescribed displacement and perform the pull-out test analyses under displacement control.

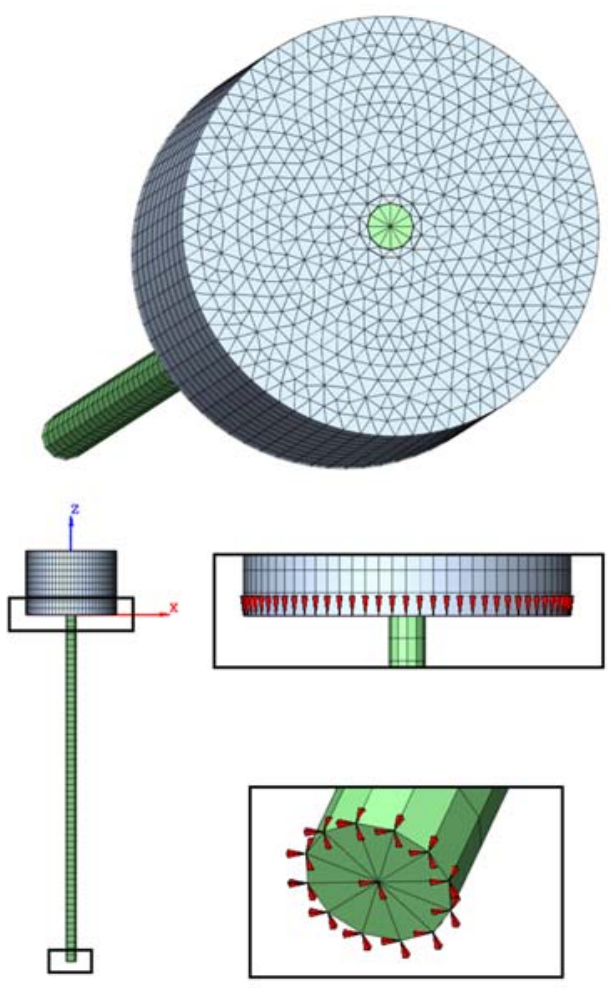

Figure 11. Meshed model used for FE non-linear analyses showing applied boundary conditions. 
A smeared crack approach was chosen to describe cracking in concrete using a total strain rotating crack model. The compressive behaviour was selected according to the model suggested by Thorenfeldt [30] for both PC and FRC. The tensile behaviour of plain concrete was governed by a softening law as proposed by Cornelissen et al. [31], using a fracture energy of $88 \mathrm{~N} / \mathrm{m}$ as calculated in Model Code 1990 [32]. The compressive strength for PC and FRC, $f_{\mathrm{c}}=46.5 \mathrm{MPa}$, as well as the tensile strength, $f_{\mathrm{ct}}=3.0 \mathrm{MPa}$, for $\mathrm{PC}$, were derived from the material characterization tests. As for the tensile behaviour of FRC, a multi-linear softening curve was used, which was obtained through inverse analysis of three-point bending tests (3PBT) as described in [33]. The experimental data used for the inverse analysis was taken from a previous investigation [22], in which an identical mix composition was used to cast three-point bending tests. The $\sigma-\mathrm{w}$ relationship obtained from the inverse analysis and the comparison of experimental and numerical results are shown in Fig. 12.
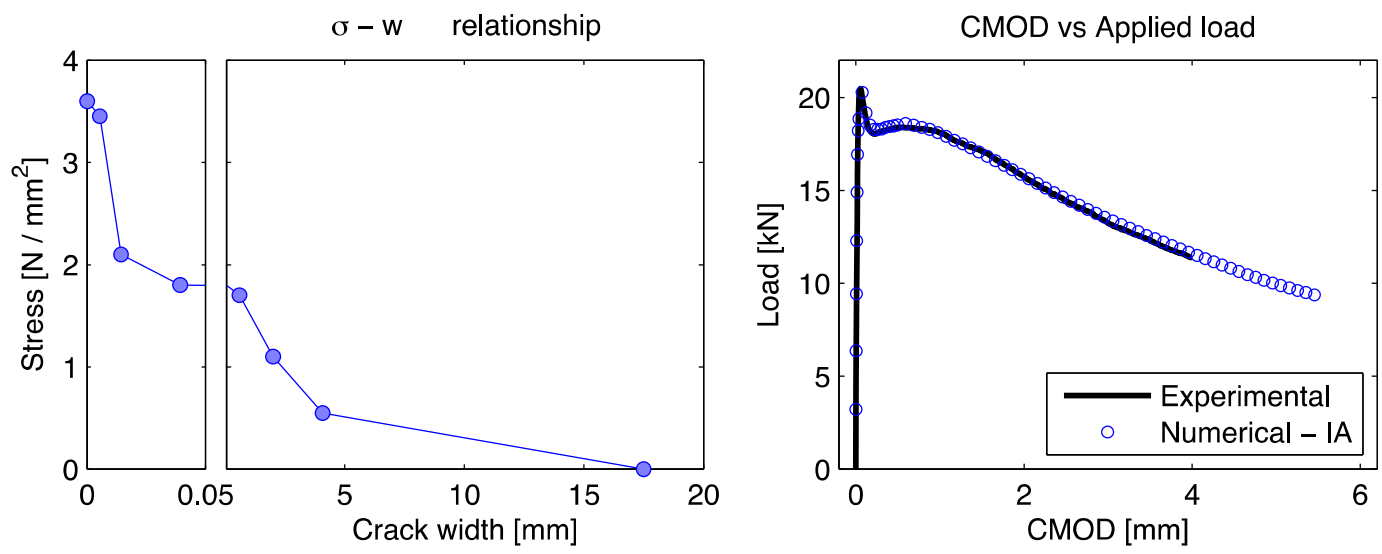

Figure 12. The $\sigma$-w relationship for the FRC obtained from Inverse Analysis of three-point bending tests (a) and a comparison of experimental and numerical results of load vs CMOD for the three-point bending tests (b).

\subsubsection{Bond and corrosion models}

The model used in this work to describe the bond mechanism was originally formulated by Lundgren et al. in [34] and further developed in [35]. The bond between concrete and reinforcement is described by a frictional model using elasto-plastic theory. The model is assigned to $2 \mathrm{D}$-interface elements generated at a zero thickness surface between the steel and concrete elements, describing the relations between stresses $\left(\sigma_{\mathrm{n}}, \tau\right)$ and relative displacements $\left(u_{n}, u_{t}\right)$ as depicted in Fig.13(a). The yield surface of the model is defined by two yield functions which are represented in Fig.13(b). The first yield function, $F_{1}$, describes the friction, where $\mu$ is the friction coefficient and $f_{a}$ is the interface adhesion. The second yield function, $F_{2}$, describes the upper limit at pull-out failure, which is determined from the crushing in the inclined compressive struts resulting from the bond action, where $c$ represents the compressive strength of the concrete. Input parameters for the bond model, adopted from [36], are presented in Table 7, whereas more detailed information about the model implementation, including the definition of flow rules and hardening laws, can be found in [35]. 

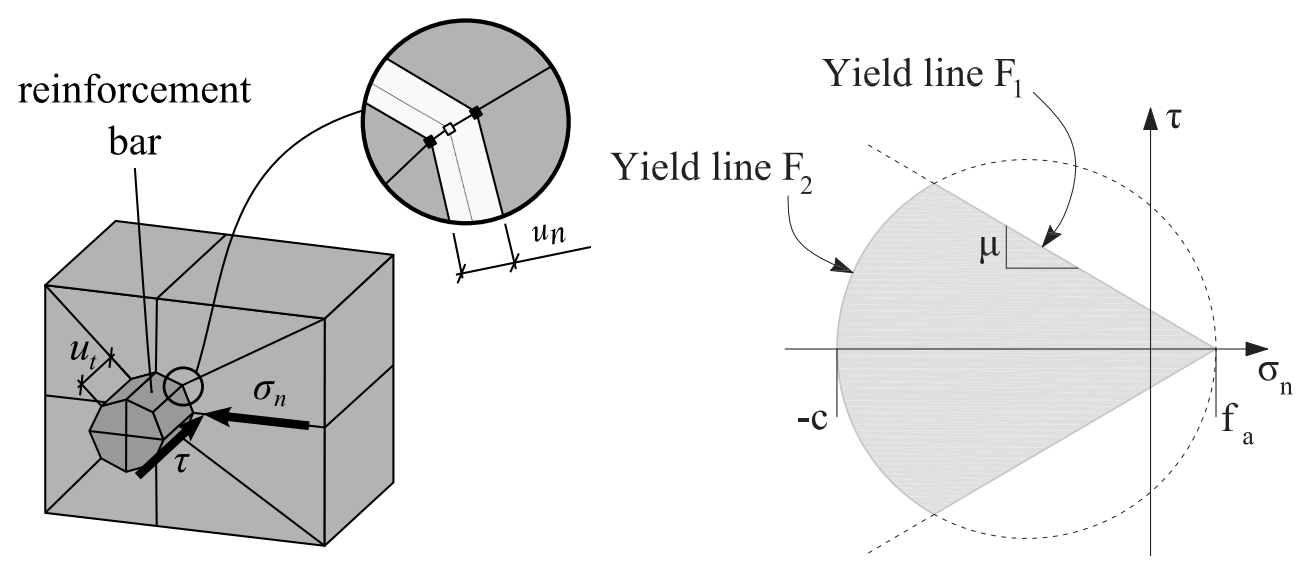

Figure 13. Relation between stresses and relative displacements at the interface (a) and yield surfaces of the frictional model (b), from [35].

The corrosion model, implemented as a part of the finite element mechanical model, describes the internal pressure in the concrete occasioned by the volumetric expansion of the corrosion products; for a detailed description see [19], whereas a validation of the model can be found in [36,37]. Taking the corrosion penetration as an input, the model calculates a free radial expansion of the rebar based on the assumed volume ratio between the corrosion products and the base metal. Since the expansion of the corrosion products is constrained by the concrete, the real expansion will be smaller and normal stresses appear at the steel-concrete interface. By imposing equilibrium and compatibility conditions between the interface and concrete elements, a stress state consisting of compressive radial stresses and tensile circumferential stresses is generated, which depend on the mechanical properties assigned to the corrosion products as well as on the fracture state of the concrete, modelled by a smeared crack approach. The analysis in the corrosion phase is carried out in time steps, modelling the swelling and cracking of the corrosion. The interaction between corrosion and bond is also accounted for by reducing the friction coefficient as the corrosion level increases, simulating the removal of the reinforcement ribs. The input parameters for the corrosion model, adopted from [36], are presented in Table 7.

\section{Discussion of numerical results}

\subsection{Crack initiation}

The corrosion model used in the 3D finite element analyses, successfully reproduced the formation of splitting cracks stemming from the internal pressure exerted by the expanding corroding rebar for both PC and FRC. However, the model overestimated the corrosion level at crack onset compared to experimental results. This discrepancy between experimental and numerical results might be attributed to the volume ratio of corrosion products (to iron) adopted by the model. Caré et al. [38], investigated the mechanical properties of the rust layer formed under impressed current using very similar test conditions to the ones of the present study and determined that the volume of corrosion products was nearly 6.5 times greater than that of iron. Even though part of the rust may diffuse through the concrete pores near the reinforcement bar, as discussed in [39], the volumetric expansion coefficient of 2, adopted in the model, could still be too low for the conditions investigated. 
Table 7. Input parameters used in the bond and corrosion models adopted from [36].

\begin{tabular}{|c|c|c|c|}
\hline \multicolumn{4}{|c|}{ Bond model } \\
\hline $\begin{array}{l}\text { Hardening } \\
\text { parameter } \kappa \\
\quad[\mathrm{mm}]\end{array}$ & $\begin{array}{l}\text { Stress in } \\
\text { compressive strut } \\
c(\kappa) \\
{[\mathrm{Mpa}]}\end{array}$ & $\begin{array}{l}\text { Coefficient of } \\
\text { friction } \\
\mu(\kappa) \\
{[-]}\end{array}$ & $\begin{array}{l}\text { Adhesive strength } \\
\qquad f_{a}(\kappa) \\
{[\mathrm{Mpa}]}\end{array}$ \\
\hline 0 & 46.5 & 1 & 3.36 \\
\hline 0.64 & 46.5 & 0.98 & 0 \\
\hline 1.07 & 46.0 & 0.87 & 0 \\
\hline 1.51 & 45.6 & 0.80 & 0 \\
\hline 1.90 & 44.6 & 0.75 & 0 \\
\hline 2.60 & 42.8 & 0.68 & 0 \\
\hline 4.71 & 34.9 & 0.55 & 0 \\
\hline 12.1 & 4.65 & 0.40 & 0 \\
\hline $1.5 \times 10^{17}$ & 0 & 0.40 & 0 \\
\hline \multicolumn{4}{|c|}{ Corrosion model } \\
\hline \multirow{4}{*}{\multicolumn{3}{|c|}{$\begin{array}{l}\text { Volume of rust relative to uncorroded steel } \\
\text { Parameters describing the mechanical behaviour of the rust }\end{array}$}} & $v=2.0$ \\
\hline & & & $\sigma_{\mathrm{n}}=K_{\mathrm{corr}} \varepsilon_{\mathrm{corr}}^{p}$ \\
\hline & & & $K_{\text {corr }}=14 \mathrm{GPa}$ \\
\hline & & & $p=7.0$ \\
\hline
\end{tabular}

After crack formation, the opening of cracks caused by increasing corrosion level occurred more rapidly in the analyses than in the experiments. Besides, for PC specimens, the model could not reach the higher corrosion levels achieved in the experiments due to complete loss of stress transfer through the fragments in which the concrete cylinder split. Both of these issues indicate that once cracking occurs the internal pressure of corrosion is alleviated and the expansion of the rebar does not continue growing at the same rate, which might be attributed to the transport of corrosion products into the formed cracks. In the model, this issue could be dealt with by e.g. updating the volumetric expansion coefficient of the corrosion products during the analysis based on the cracking state of the concrete surrounding the rebar. Nevertheless, the crack pattern obtained from the 3D models, presented in Fig. 14, was in good agreement with the crack pattern observed in the experiments, shown in Fig. 7.

The numerical results also showed that the greater confinement provided by the large concrete cover, not only slowed down the crack propagation but it also enabled the simultaneous formation of secondary cracks along with the main crack, whereas for specimens with a smaller cover, a single crack developed first and secondary cracks occurred later. Changing the material model of the concrete to incorporate the effect of the fibres introduced an additional source of confinement, promoting the appearance of multiple cracks and retarding their propagation, which had a significant impact on specimens with small cover and low initial confinement but a rather limited influence on specimens with larger cover. Consequently, the greater efficiency of fibres in delaying the initiation of corrosion-induced splitting cracks in specimens with reduced concrete covers can be attributed to a significant contribution of the fibres to the passive confinement of the rebar, effect that is reduced as the confinement provided by the cover increases. It should be noted that there might have been 
some wall effects affecting the fibre orientation and efficiency. However, considering the dimensions of the specimens used, a significant effect is not likely since most of the crack delaying effect is due to fibres close the rebar where small differences are expected.

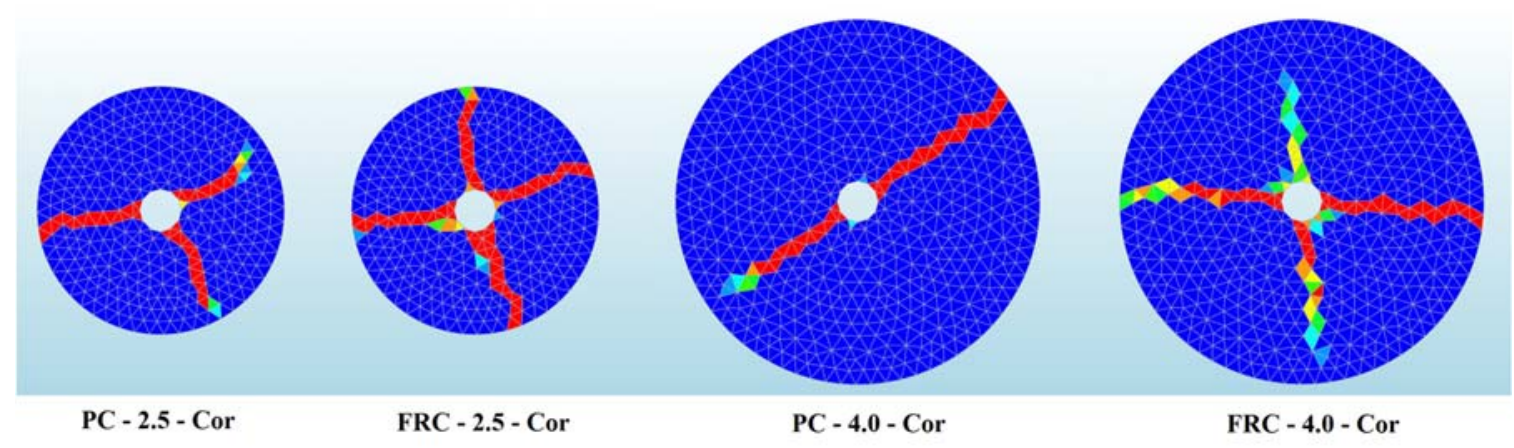

Figure 14. Top view of the crack pattern at a high corrosion stage obtained from 3D FE models. Red colour indicates cracks with a crack width equal to or greater than $0.1 \mathrm{~mm}$.

\subsection{Pull-out behaviour}

\subsubsection{One dimensional model}

The average anchorage lengths obtained from the 1D model are summarized in Table 8, whereas Fig. 15 shows the reduction of anchorage length in FRC compared to PC to fully anchor the yield strength of the rebar, expressed as the fraction of length needed for $\mathrm{PC}$ and calculated as:

$$
\eta_{L}=\frac{L_{F R C}}{L_{P C}}
$$

where $L_{F R C}$ and $L_{P C}$ are the average anchorage lengths for FRC and PC, respectively.

Table 8. Average anchorage length calculated with the1D model using the experimental bond-slip relations as input, in $\mathbf{m m}$.

\begin{tabular}{cccc}
\hline $\mathrm{c} / \varnothing$ & Stage & $L_{\mathrm{PC}}$ & $L_{\mathrm{FRC}}$ \\
\hline \multirow{4}{*}{2.5} & Reference & 209 & 146 \\
& Cracking & 203 & 141 \\
& Corroded & 586 & 157 \\
\hline \multirow{4}{*}{4.0} & Reference & 137 & 128 \\
& Cracking & 191 & 110 \\
& Corroded & 984 & 136 \\
\hline
\end{tabular}




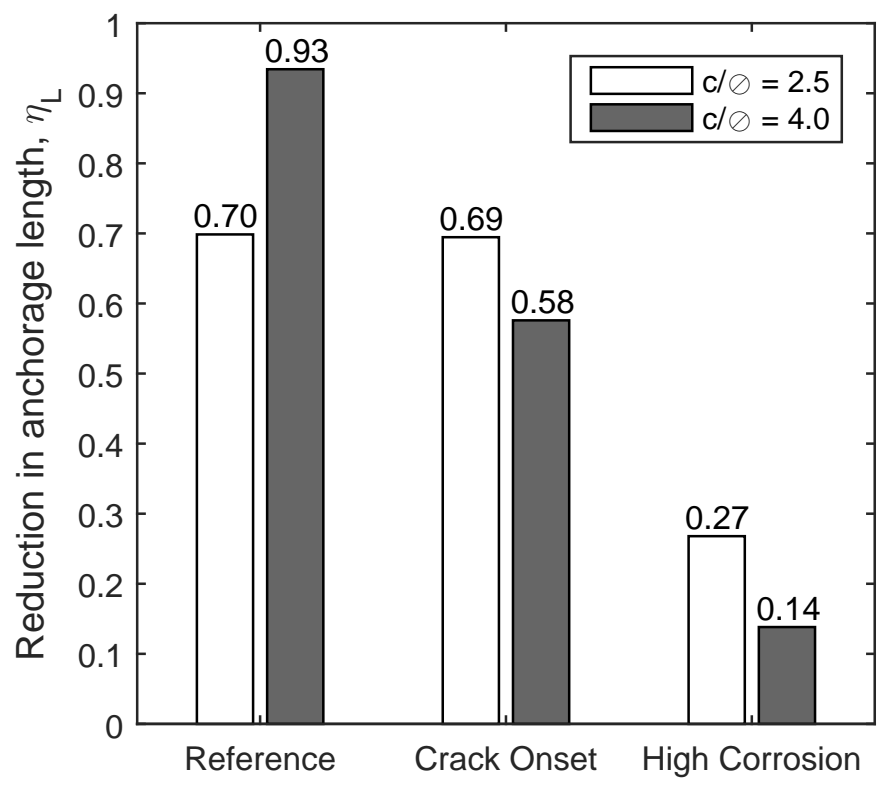

Figure 15. Reduction in the length of bar needed to anchor the yield strength of a $\varnothing 16 \mathrm{~mm}$ rebar with yield stress $550 \mathrm{MPa}$ in FRC compared to PC, determined through 1D numerical analysis using the experimental bond-slip as input.

The analysis of the anchorage length presented in Table 8 revealed that for FRC the necessary anchorage length was, in practice, constant throughout the different corrosion stages, and only a small reduction was achieved by increasing the $c / \varnothing$. This can be attributed to the small variation observed for the splitting strength and the significant amount of post-peak bond stress in all the FRC specimens at varying corrosion levels. For PC specimens the effect of cracking and high corrosion was dependent on the $c / \varnothing$. Whereas the anchorage length for small covers was almost triplicated at high corrosion levels, crack initiation did not significantly alter it. However, specimens with a large cover were much more sensitive to the effects of corrosion, showing an increasing anchorage length for increasing corrosion levels up to seven times the anchorage length of the reference specimens.

Looking at Fig. 15, the beneficial effect of fibres on the reduction in anchorage length becomes clear. As a result of the limited initial confinement provided by the cover of the smaller cylinders, the addition of fibres resulted in an anchorage length reduction of $30 \%$ at an uncorroded stage, whereas that effect was not as evident for large specimens due to the higher confinement provided by the concrete cover. These results show that as the cover increases and approaches "well confined" conditions ( $c / \varnothing=5$ according to Model Code 2010 [40]), the beneficial effect of the fibres on the anchorage length decreases, which is in line with results reporting that low fibre contents will not significantly influence the behaviour of RC elements exhibiting pull-out failure $[11,17]$. However, the appearance of corrosion-induced cracks changed that trend, resulting in a greater beneficial effect of fibres for larger specimens. Increasing the corrosion level, accentuated that effect regardless of the cover depth, achieving length reductions of $73 \%$ and $86 \%$ for 2.5 and $4.0 \mathrm{c} / \varnothing$, respectively. It should be noted that these values are only used to illustrate the beneficial confinement effect of the fibres whereas they do not represent a realistic reduction of anchorage length in a real structure where the loss of confinement would be controlled by transverse reinforcement. 


\subsubsection{Three-dimensional non-linear finite element analyses}

As for the 3D FE models of the pull-out tests, the analyses were run in two phases: first, a certain corrosion level was applied allowing the rebar to expand and crack the concrete; subsequently the mechanical pull-out of the bar was performed. Since cracking did not occur in the FE models for the corrosion levels determined experimentally, a greater corrosion level was applied in the analyses to achieve the same cracking state during the pull-out phase of the Group II. Similarly, for the pull-out phase of the Group III, the corrosion levels were also adjusted to achieve a crack width in the analyses equal to the measured experimentally.

The bond-slip relations obtained from the analyses are presented in Fig. 16 for specimens with a $c / \varnothing$ $=2.5$ and in Fig. 17 for specimens with a $c / \varnothing=4.0$. Note that in Fig. 17, the results of the Group III are omitted because numerical divergence of the model occurred during the corrosion phase before reaching the target crack widths.
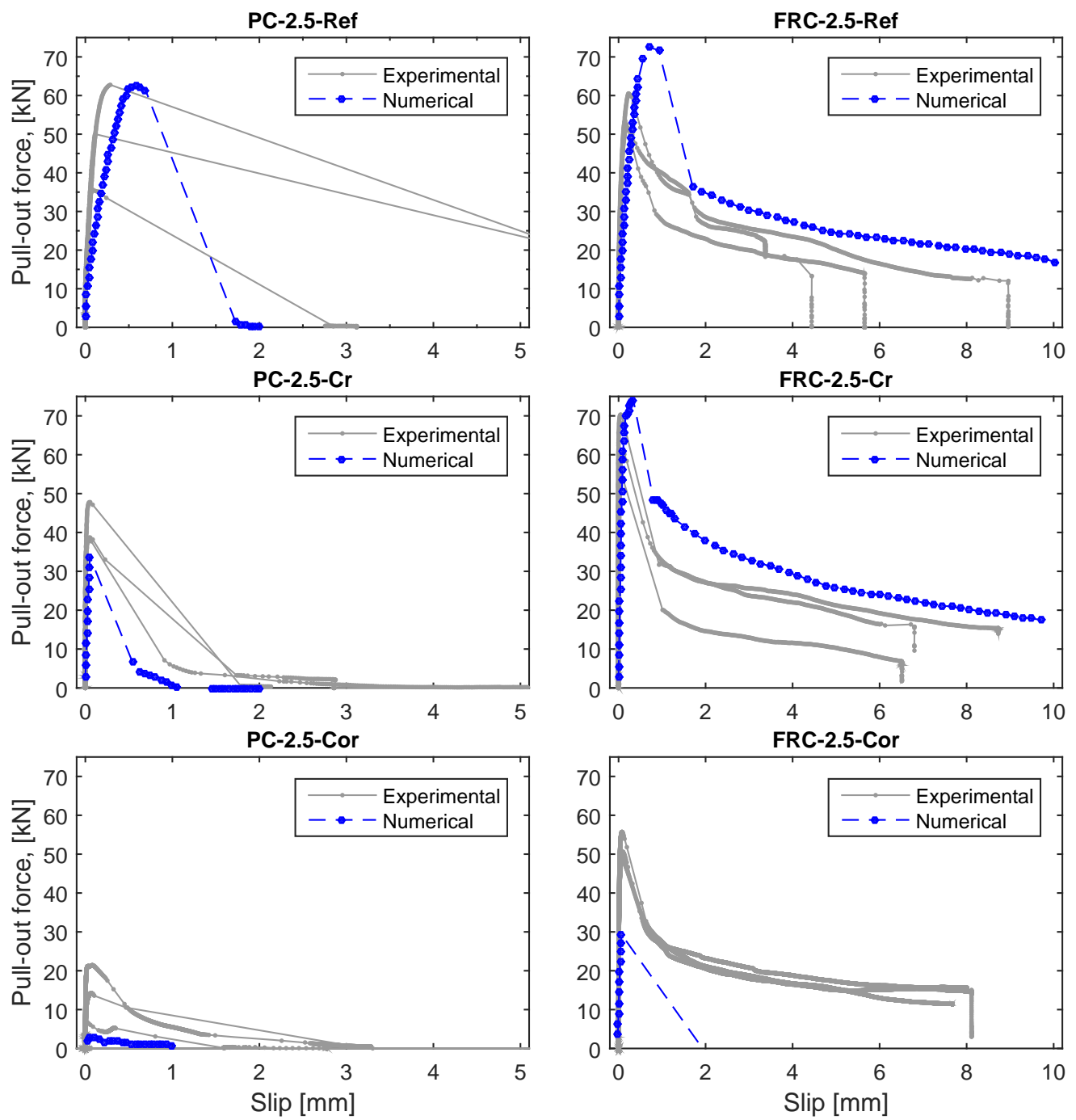

Figure 16. Comparison of experimental results and numerical simulations of pull-out tests for specimens with $c / \emptyset=2.5$. 
Overall, the numerical results successfully reproduce the general trend displayed by the experimental results, for both PC and FRC, capturing the characteristic failure mode of each mix type. However, the model tended to overestimate the peak bond-stress and the associated slip in the uncorroded stage, whereas it clearly underestimated the bond capacity for high corrosion levels. For the Group II, the numerical and experimental results are in good agreement, with the exception of the FRC-4.0-Cr specimens, which did not show the characteristic post-peak behaviour of FRC mixes as the analysis failed to reach convergence.

A reason for the overestimation of the bond capacity in the uncorroded specimens could be attributed to the choice of the coefficient of friction in the model. Jansson et al. [16] proposed a different curve for the coefficient of friction versus the hardening parameter, roughly equal to the slip: this curve quickly decreased with increasing slips, resulting in a lower bond strength. However, in order to compensate for the loss of friction, the elastic stiffness of the interface was significantly increased, which made the model less stable in analyses with corrosion. A better approach to improve the agreement could be, for instance, to modify the yield surface, $F_{l}$, in order to have a rounded shape for tensile normal stresses.
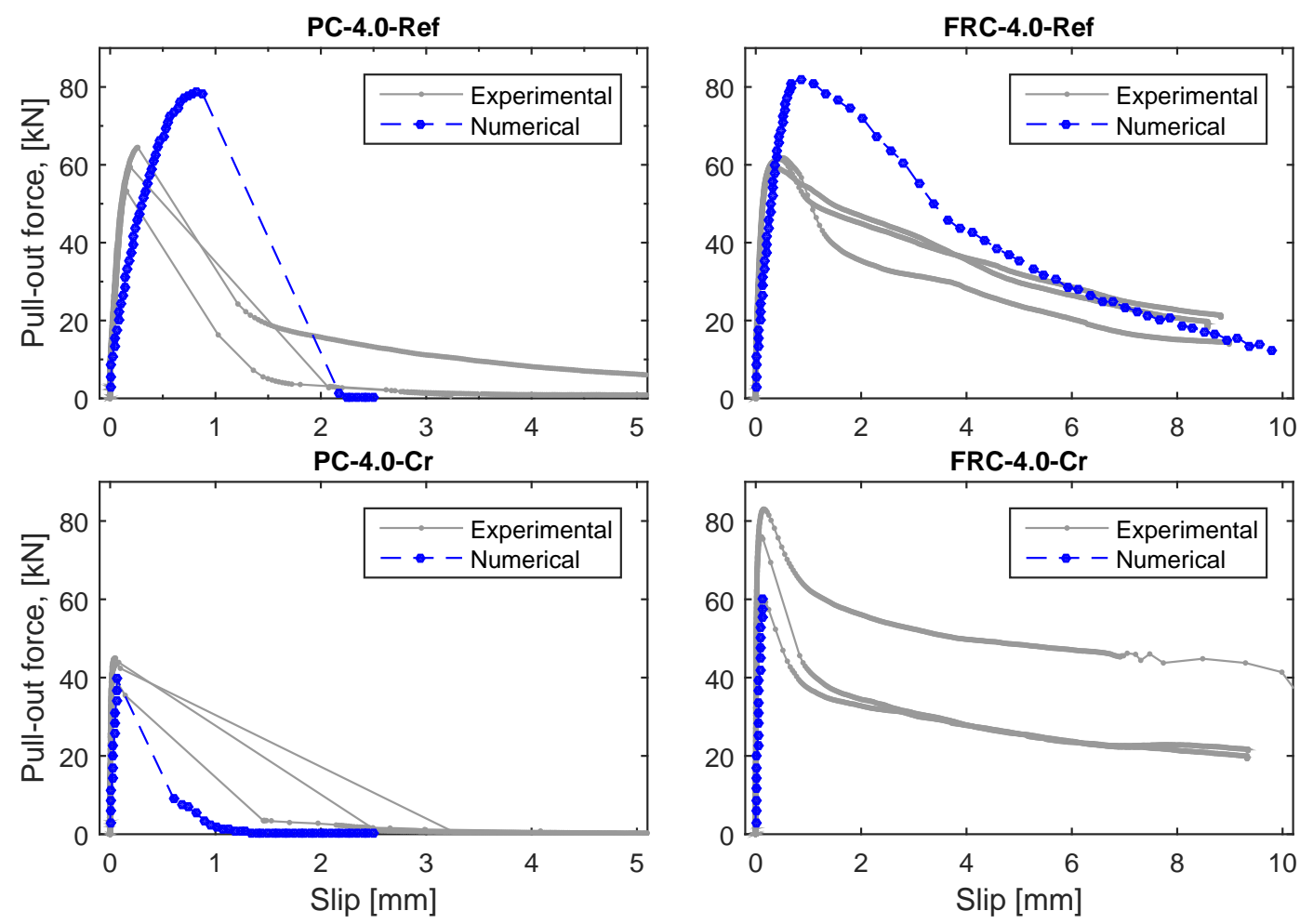

Figure 17. Comparison of experimental results and numerical simulations of pull-out tests for specimens with $c / \varnothing=4.0$.

The underestimation of the bond capacity at higher corrosion levels by the model is probably due to an excessive degradation of the concrete surrounding the rebar caused by the high pressure induced during the corrosion phase. As stated earlier in Section 5.1, this seems a direct consequence of the assumption that the volumetric expansion coefficient is kept constant during the analysis, even after cracking of the concrete cover. 


\section{Conclusions}

This paper reports experimental results regarding the corrosion level associated to the initiation of splitting cracks in PC and FRC, as well as results of pull-out tests with short-embedment length carried out for both PC and FRC at various corrosion stages. Numerical predictions were also made using both a 1D model based on the solution of the equilibrium equation between steel and concrete with experimental bond-slip relations as input and a bond-corrosion model implemented for 3D nonlinear FE analyses. Based on the results of the study, the following conclusion may be drawn:

(1) The use of steel fibres at a $0.5 \%$ vol. dosage provided an additional source of passive confinement that delayed corrosion-induced cracking. This effect was more noticeable in specimens with a smaller $c / \varnothing$, whereas it became less apparent for larger $c / \varnothing$ in which the cover already provided a significant confinement to the rebar.

(2) After cracking, fibre reinforced specimens consistently showed reduced crack widths compared to plain concrete specimens, cracks being around half as wide at corrosion levels approaching $8 \%$.

(3) As expected, for uncorroded specimens, the results from the pull-out tests showed no significant difference between PC and FRC specimens regarding the splitting strength. For increasing corrosion levels, however, the splitting strength of PC specimens exhibited a clear degradation, particularly for specimens with a larger cover. Conversely, FRC specimens retained their initial splitting strength at $8 \%$ corrosion and even showed a slight increase at intermediate corrosion levels.

(4) The pull-out tests revealed a clear contribution of the fibres on the post-peak capacity regardless of the size and corrosion level. Based on the 1D analyses, the anchorage length in FRC specimens subjected to $8 \%$ corrosion was only increased by $10 \%$ compared to uncorroded reference specimens, unlike for PC specimens in which the anchorage length at the same corrosion level increased by a factor ranging from three to seven.

(5) Fibre reinforcement proved to be an effective means of preventing spalling of the concrete cover, understood as both its physical detachment and the loss of its mechanical contribution to the structure.

(6) The applicability to FRC of an existing bond-corrosion model, originally intended for plain concrete was investigated. The bond-corrosion model was capable of reproducing realistic crack patterns similar to those generated during the corrosion phase in the experiments. Likewise, the model was able to capture the failure mode of the different PC and FRC specimens during the pull-out tests. However, the applicability of the corrosion model in its present stage is limited to moderate corrosion levels while the obtained results differed from the experiments in terms of the corrosion level inducing cracking and the relation between crack width and corrosion. 


\section{References}

[1] I. Fernandez, J.M. Bairán, A.R. Marí, Mechanical model to evaluate steel reinforcement corrosion effects on $\sigma-\varepsilon$ and fatigue curves. Experimental calibration and validation, Eng. Struct. 118 (2016) 320-333.

[2] I. Fernandez, M. Etxeberria, A.R. Marí, Ultimate bond strength assessment of uncorroded and corroded reinforced recycled aggregate concretes, Constr. Build. Mater. 111 (2016) 543555 .

[3] A. Jansson, M. Flansbjer, I. Löfgren, K. Lundgren, K. Gylltoft, Experimental investigation of surface crack initiation, propagation and tension stiffening in self-compacting steel-fibrereinforced concrete, Mater. Struct. 45 (2012) 1127-1143.

[4] H. Abrishami, D. Mitchell, Influence of steel fibers on tension stiffening, ACI Struct. J. 94 (1997) 769-776.

[5] M. Di Prisco, G. Plizzari, L. Vandewalle, Fibre reinforced concrete: new design perspectives, Mater. Struct. 42 (2009) 1261-1281.

[6] J. Blunt, G. Jen, C.P. Ostertag, Enhancing corrosion resistance of reinforced concrete structures with hybrid fiber reinforced concrete, Corros. Sci. 92 (2015) 182-191.

[7] M. Maalej, S.F.U. Ahmed, P. Paramasivam, Corrosion Durability and Structural Response of Functionally-Graded Concrete Beams, J. Adv. Concr. Technol. 1 (2003) 307-316.

[8] H. Mihashi, S.F.U. Ahmed, A. Kobayakawa, Influence of crack widths on corrosion of reinforcing steel bar in fiber reinforced cementitious composites, in: Int. RILEM Conf. Adv. Constr. Mater. Through Sci. Eng., Hong Kong, CHina, on 5-7 September, 2011: p. n/a.

[9] B. Šavija, M. Luković, J. Pacheco, E. Schlangen, Cracking of SHCC due to reinforcement corrosion, Proc. 9th Int. Conf. Fract. Mech. Concr. Concr. Struct. (2016).

[10] J. Cairns, G.A. Plizzari, Bond of Reinforcement in Fibre Reinforced Concrete, in: 6th RILEM Symp. Fibre-Reinforced Cocnretes - BEFIB 2004, Verenna, Italy, 2004: pp. 321-330.

[11] G. Campione, C. Cucchiara, L. La Mendola, M. Papia, Steel-concrete bond in lightweight fiber reinforced concrete under monotonic and cyclic actions, Eng. Struct. 27 (2005) 881-890.

[12] S. Chao, A.E. Naaman, G.J. Parra-montesinos, Local Bond Stress - Slip Models for Reinforcing Bars \& Prestressing Strands in High- High - Performance Fiber Reinforced Cement Composites ( HPFRCCs ), (n.d.).

[13] L. Huang, Y. Chi, L. Xu, P. Chen, A. Zhang, Local bond performance of rebar embedded in steel-polypropylene hybrid fiber reinforced concrete under monotonic and cyclic loading, Constr. Build. Mater. 103 (2016) 77-92.

[14] A.S. Ezeldin, P.N. Balaguru, Bond Behavior of Normal and High . Strength Fiber Reinforced Concrete, (1990) 515-524.

[15] M.H. Harajli, M. Hout, W. Jalkh, Local Bond Stress-Slip Behavior of Reinforcing Bars Embedded in Plain and Fiber Concrete, ACI Mater. J. 92 (1995) 343-354.

[16] A. Jansson, I. Lofgren, K. Lundgren, K. Gylltoft, Bond of reinforcement in self-compacting steel-fibre-reinforced concrete, Mag. Concr. Res. 64 (2012) 617-630.

[17] M.H. Harajli, M.E. Mabsout, Evaluation of bond strength of steel reinforcing bars in plain 
and fiber-reinforced concrete, ACI Struct. J. 99 (2002) 509-517.

[18] R.H. Haddad, A.M. Ashteyate, Role of synthetic fibers in delaying steel corrosion cracks and improving bond with concrete, Can. J. Civ. Eng. 28 (2001) 787-793.

[19] K. Lundgren, Bond between ribbed bars and concrete. Part 2: The effect of corrosion, Mag. Concr. Res. 57 (2005) 383-395.

[20] EN 12390-3:2009 Testing hardened concrete. Part 3: Compressive strength of test specimens, (2009).

[21] EN 12390-6:2001 Testing hardened concrete. Tensile splitting strength of test specimens, (2001).

[22] C.G.. Berrocal, I. Löfgren, K. Lundgren, N. Görander, C. Halldén, Characterisation of bending cracks in R/FRC using image analysis, Submitt. to Mater. Struct. (2016).

[23] EN 14651:2007 Test method for metallic fibered concrete - Measuring the flexural tensile strength (limit of proportionality (LOP), residual), (2007).

[24] T. El Maaddawy, K. Soudki, A model for prediction of time from corrosion initiation to corrosion cracking, Cem. Concr. Compos. 29 (2007) 168-175.

[25] ASTM G1, Standard Practice for Preparing, Cleaning, and Evaluating Corrosion Test, 1999.

[26] A. Michel, B. Pease, H. Stang, Cracking and durability in ( fiber reinforced ) cement-based materials, in: Int. Work. Fiber Reinf. Concr. Mater. Prop. Des. Guidel. Appl. Novemb. 17-18, Standford, USA, 2014.

[27] TNO Diana, Finite Element Analysis, Diana User's Manual 9.6, (2015).

[28] K. Lundgren, P. Kettil, K.Z. Hanjari, H. Schlune, A.S.S. Roman, Analytical model for the bond-slip behaviour of corroded ribbed reinforcement, Struct. Infrastruct. Eng. 8 (2012) 157169.

[29] Matlab, Matlab:2014, The MathWorks Inc., Natick, Massachusetts, 2014.

[30] E. Thorenfeldt, A. Tomaszewicz, J.J. Jensen, Mechanical properties of high-strength concrete and applications in design, in: Symp. Util. High-Strength Concr., Stavanger, Norway, 1987.

[31] H.A.W. Cornelissen, D.A. Hordijk, H.W. Reinhardt, Experimental Determination of Crack Softening Characteristics of Normalweight and Lightweight Concrete., Heron. 31 (1986) 4556.

[32] Comite Euro-International Du Beton, CEB-FIP Model Code 1990: Design Code, in: CEBFIP Model CODE 1990, Thomas Telford Publishing, 1993: pp. i-xxii.

[33] I. Löfgren, H. Stang, J.F. Olesen, Fracture Properties of FRC Determined through Inverse Analysis of Wedge Splitting and Three-Point Bending Tests, J. Adv. Concr. Technol. 3 (2005) 423-434.

[34] K. Lundgren, K. Gylltoft, A model for the bond between concrete and reinforcement, Mag. Concr. Res. 52 (2000) 53-63.

[35] K. Lundgren, Bond between ribbed bars and concrete. Part 1: Modified model, Mag. Concr. Res. 57 (2005) 371-382.

[36] K. Lundgren, Effect of corrosion on the bond between steel and concrete: an overview, Mag. Concr. Res. 59 (2007) 447-461. 
[37] C. Fang, K. Lundgren, M. Plos, K. Gylltoft, Bond behaviour of corroded reinforcing steel bars in concrete, Cem. Concr. Res. 36 (2006) 1931-1938.

[38] S. Caré, Q.T. Nguyen, V. L'Hostis, Y. Berthaud, Mechanical properties of the rust layer induced by impressed current method in reinforced mortar, Cem. Concr. Res. 38 (2008) 10791091.

[39] A. Michel, B.J. Pease, M.R. Geiker, H. Stang, J.F. Olesen, Monitoring reinforcement corrosion and corrosion-induced cracking using non-destructive $\mathrm{x}$-ray attenuation measurements, Cem. Concr. Res. 41 (2011) 1085-1094.

[40] Model Code, fib Model Code for Concrete Structures, Wiley-VCH Verlag GmbH \& Co. KGaA, Weinheim, Germany, 2010. 